\title{
Translating recent results from the Cardiovascular Outcomes Trials into clinical practice: recommendations from the Central and Eastern European Diabetes Expert Group (CEEDEG)
}

Guntram Schernthaner ${ }^{1 *}$, Roger Lehmann², Martin Prázný3 ${ }^{3}$ Leszek Czupryniak ${ }^{4}$, Kristine Ducena ${ }^{5}$, Peter Fasching ${ }^{6}$, Andrej Janež ${ }^{7}$, Avraham Karasik ${ }^{8}$, Peter Kempler ${ }^{9}$, Emil Martinka ${ }^{10}$, Marina V. Shestakova ${ }^{11}$, Lea Smirčić Duvnjak ${ }^{12}$ and Tsvetalina Tankova ${ }^{13}$

\begin{abstract}
Aims: These recommendations aim to improve care for patients with type 2 diabetes (T2D) at high cardiovascular (CV) risk in Central and Eastern Europe. Cardiovascular disease (CVD) and/or chronic kidney disease (CKD) are major interdependent comorbidities in patients with T2D, accounting for 50\% of mortality. Following recent CV outcomes trial (CVOT) results, including those from EMPA-REG OUTCOME ${ }^{\circledR}$, LEADER ${ }^{\circledR}$, SUSTAIN ${ }^{\mathrm{TM}}-6$ and, most recently, the CANVAS study, it is essential to develop regional expert consensus recommendations to aid physicians in interpreting these newest data to clinical practice.

Methods: The Central and Eastern European Diabetes Expert Group (CEEDEG) followed a Delphi method to develop treatment algorithms to aid physicians in the clinical management of patients with T2D at high CV risk.

Results: In light of the latest CVOT results, and in particular the EMPA-REG OUTCOME ${ }^{\circledR}$ and LEADER $^{\circledR}$ trials, the diagnosis, assessment, treatment choice and monitoring of patients with T2D and established CVD and/or CKD have been considered together with existing guidelines and presented in two reference algorithms. In addition, adherence, special prescribing considerations and a proposed multidisciplinary management approach have been discussed and are presented with the proposed algorithms.

Conclusions: The latest available high-level evidence on glucose-lowering drugs has enabled CEEDEG to develop practical consensus recommendations for patients with established CVD and/or CKD. These recommendations represent an update to international and country-level guidelines used for these patients, with the aim of providing a resource not only to endocrinologists, but to cardiologists, nephrologists and primary care physicians in the region.
\end{abstract}

Keywords: Type 2 diabetes, Anti-glycaemic drugs, Cardiovascular disease, Renal disease

\section{Background}

For patients with type 2 diabetes (T2D), cardiovascular disease (CVD) is the single most common cause of mortality [1]. The average life expectancy of a 60 -year-old

\footnotetext{
*Correspondence: guntram.schernthaner@meduniwien.ac.at ${ }^{1}$ Department of Medicine I, Rudolfstitung Hospital, Vienna, Austria Full list of author information is available at the end of the article
}

male with T2D and no history of cardiovascular (CV) disease (CVD) is 12 years less than his counterpart without diabetes, mostly owing to a $58 \%$ increase in risk of CV death [2].

Historical studies investigating the potential benefits of intensive glucose-lowering therapy have shown mixed results $[3,4]$, and concerns were raised that some 
anti-diabetic agents might even be increasing $\mathrm{CV}$ risk in patients with T2D; a particular concern in light of the high prevalence of $\mathrm{CV}$ and/or renal co-morbidities in this patient population. Meta-analyses revealed that rosiglitazone was associated with a significant increase in the risk of myocardial infarction (MI) compared with patients not receiving rosiglitazone, and an increase in the risk of $\mathrm{CV}$ death that had borderline significance $[5,6]$. The later US veterans affairs diabetes trial showed, however, that rosiglitazone use in older patients with T2D was associated with decreased risk of the primary CV composite outcome and $\mathrm{CV}$ death, and that rosiglitazone use did not lead to a higher risk of MI [7]. Meta-analyses across study results are not designed to assess superiority, are not prospective and are likely to necessitate the inclusion of heterogeneous study designs. To address this safety concern, the US Food and Drug Administration (FDA) and the European Medicines Agency (EMA) have therefore asked for proof of $\mathrm{CV}$ safety, which includes $\mathrm{CV}$ outcomes trials (CVOTs) being initiated on all new anti-diabetic agents to provide prospective, statistically powered assessments in patients with T2D in order to rule out excess CV risk [8-10].

CVOTs for several anti-diabetic drugs have been published in the past few years. Although these new antidiabetic agents generated mostly neutral CV outcomes, providing welcome evidence that most of these drugs do not increase $\mathrm{CV}$ risk for patients with T2D, there were mixed results overall, as shown in Table $1[4,10]$.

In light of these mixed results, the swift incorporation of CVOT findings into international and country-level guidelines is therefore necessary to facilitate treatment decisions for improved patient outcomes. Many guidelines for the treatment of T2D require further updates, including, importantly, the Joint Position Statement of the European Association for the Study of Diabetes (EASD)/American Diabetes Association (ADA) and the American College of Physicians (ACP) $[11,12]$. The guidelines of the European Society of Cardiology (ESC) and the ADA, however, have recently incorporated recommendations based on the CVOT results $[13,14]$. The Central and Eastern European Diabetes Expert Group (CEEDEG) was created as a responsive team of experts, providing regular and up-to-date clinical recommendations to be used as a companion resource for the region, together with the EASD/ADA position statement. By providing such regular follow-up publications, it is anticipated that important data on safety and both positive and negative outcomes can be rapidly disseminated. CEEDEG is composed of 14 members, six of whom have been involved in the generation of their national clinical guidelines, including the Swiss Society of Endocrinology and Diabetes (SSED/SGED) [15], the Hungarian Diabetology Society [16], the Slovak Diabetes Association [17], the Russian Association of Endocrinologists [18], and the Austrian Society for Diabetes (ÖDG) $[15,19]$. All members hold senior positions in medical schools in their respective countries and belong to, or serve on, a variety of professional bodies throughout Central and Eastern Europe. The recommendations herein have been derived via a Delphi process, which is a structured tool to achieve unbiased consensus [20].

\section{Methods}

CEEDEG was formed to provide a panel of experts in Central and Eastern Europe who could regularly review, interpret and translate new data from clinical studies into clinical recommendations for everyday practice.

The process was structured to generate expert clinical recommendations to complement the current EASD/ADA

Table 1 Key cardiovascular and renal outcomes for CVOTs of glucose-lowering agents

\begin{tabular}{|c|c|c|c|c|c|}
\hline & $\begin{array}{l}\text { Reduction in } \\
\text { 3-point MACE }\end{array}$ & $\begin{array}{l}\text { Reduction in } \\
\text { CV death }\end{array}$ & $\begin{array}{l}\text { Reduction in } \\
\text { all-cause mortality }\end{array}$ & $\begin{array}{l}\text { Reduction in } \\
\text { hospitalisation for HF }\end{array}$ & $\begin{array}{l}\text { Reduction in doubling } \\
\text { of serum creatinine }\end{array}$ \\
\hline \multicolumn{6}{|c|}{ EMPA-REG OUTCOME ${ }^{\circledR}$} \\
\hline RRR (\%) & 14 & 38 & 32 & 35 & 44 \\
\hline$p$ value & 0.04 & $<0.001$ & $<0.001$ & 0.002 & $<0.001$ \\
\hline \multicolumn{6}{|l|}{ LEADER $^{\circledR}$} \\
\hline $\operatorname{RRR}(\%)$ & 13 & 22 & 15 & 13 & 12 \\
\hline$p$ value & 0.01 & 0.007 & 0.02 & NS & NS \\
\hline \multicolumn{6}{|c|}{ SUSTAIN ${ }^{\mathrm{TM}}-6$} \\
\hline $\operatorname{RRR}(\%)$ & 26 & 2 & +5 & +11 & +28 \\
\hline$p$ value & 0.02 & NS & NS & NS & NS \\
\hline
\end{tabular}

This is not a head-to-head comparison

SUSTAIN- ${ }^{\mathrm{TM}}$ was a non-inferiority study, and testing for superiority was not a pre-specified endpoint $[22,23,25,28,29,33]$

CVOT cardiovascular outcomes trial, MACE major adverse cardiovascular events (cardiovascular death, non-fatal myocardial infarction or non-fatal stroke), RRR relative risk reduction 
guidelines in light of the data from EMPA-REG OUTCOME ${ }^{\circledR}$, LEADER $^{\circledR}$, SUSTAIN ${ }^{\mathrm{TM}}-6$ and the other CVOTs that had been published at the time of the Delphi process [21-25]. Agreeing on the necessity of producing such recommendations was an inclusive initial part of the proceedings.

A semi-structured questionnaire with multi-factor open questions was circulated (Additional file 1). The questionnaire related to patients with T2D and established cardiac and/or renal disease, as these are the patient populations who would most benefit from recommendations based on CVOT data. The recommendations generated were sorted, de-duplicated and used to create a second questionnaire (Additional file 2), in which respondents scored each proposed recommendation on a Likert-like scale (1-totally disagree; 2-disagree; 3-unsure; 4-agree; 5-totally agree). Only those recommendations for which at least $80 \%$ of respondents awarded a score of 4 or 5 were considered to have reached consensus. Respondents were encouraged to add additional comments, suggestions or refinements to the proposed statements. Additional suggestions and refinements were included in a third-round questionnaire, which was scored in the same way as the second (Additional file 3).
Following the Delphi process, a face-to-face meeting of CEEDEG was convened with the aim of reaching final consensus and addressing any outstanding issues from the process. In-depth discussions were held and grouped according to clinical expertise to refine and clarify points of particular complexity, then all members met to verify or reject statements together, thereby achieving a full and final consensus.

\section{Recommendations of CEEDEG}

CEEDEG noted that for those patients who have T2D but do not have established CVD or chronic kidney disease (CKD), the current EASD/ADA guidelines [11] should be followed as no further data on therapies for these patients have been published. However, for patients with either or both of these comorbidities, two algorithms were developed: one for patients with T2D and established CVD (Fig. 1), and the other for patients with T2D and established CKD with or without established CVD (Fig. 2). It is hoped that these additional tools will be used alongside the European guidelines as an aid to decision-making when prescribing glucose-lowering therapies. It should be
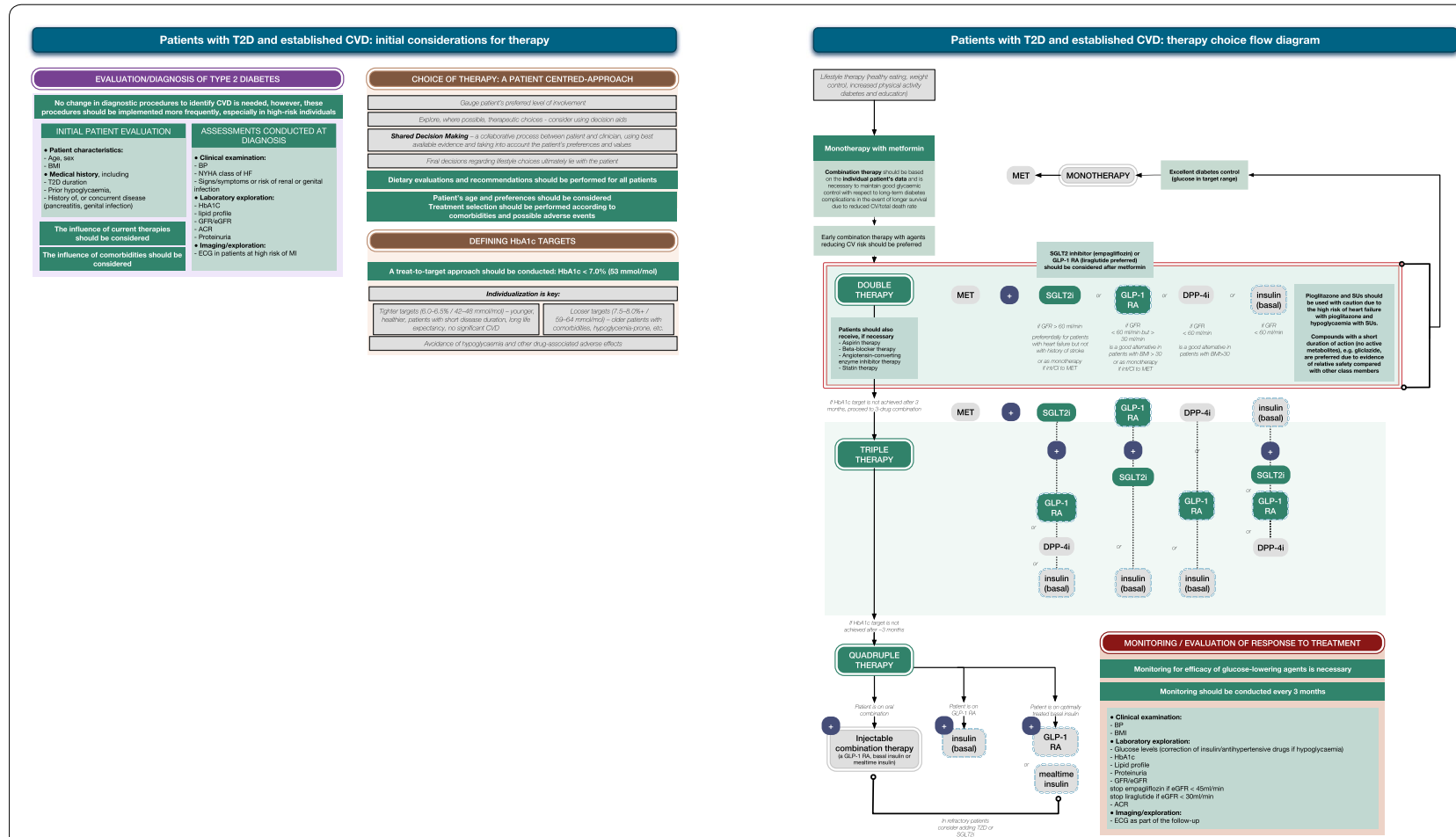

Fig. 1 Treatment algorithm for patients with type 2 diabetes (T2D) and established cardiovascular disease (CVD): initial considerations for therapy and therapy choice flow diagram. Items in green signify the items of specific focus in these recommendations. Dashed lines indicate injectable therapies. ACR albumin:creatinine ratio, BMI body mass index, BP blood pressure, CKD chronic kidney disease, CVD cardiovascular disease, DPP$4 i$ dipeptidyl peptidase 4 inhibitor, ECG electrocardiogram, GFR glomerular filtration rate, eGFR estimated GFR, DPP-4-i DPP-4 inhibitor, GLP-1 RA glucagon-like peptide 1 receptor agonist, HF heart failure, hypo hypoglycaemia, int/Cl intolerance or contraindication, MET metformin, NYHA New York Heart Association, SGLT2i sodium-glucose co-transporter 2 inhibitor, SU sulfonylurea, T2D type 2 diabetes, TZD thiazolidinedione 

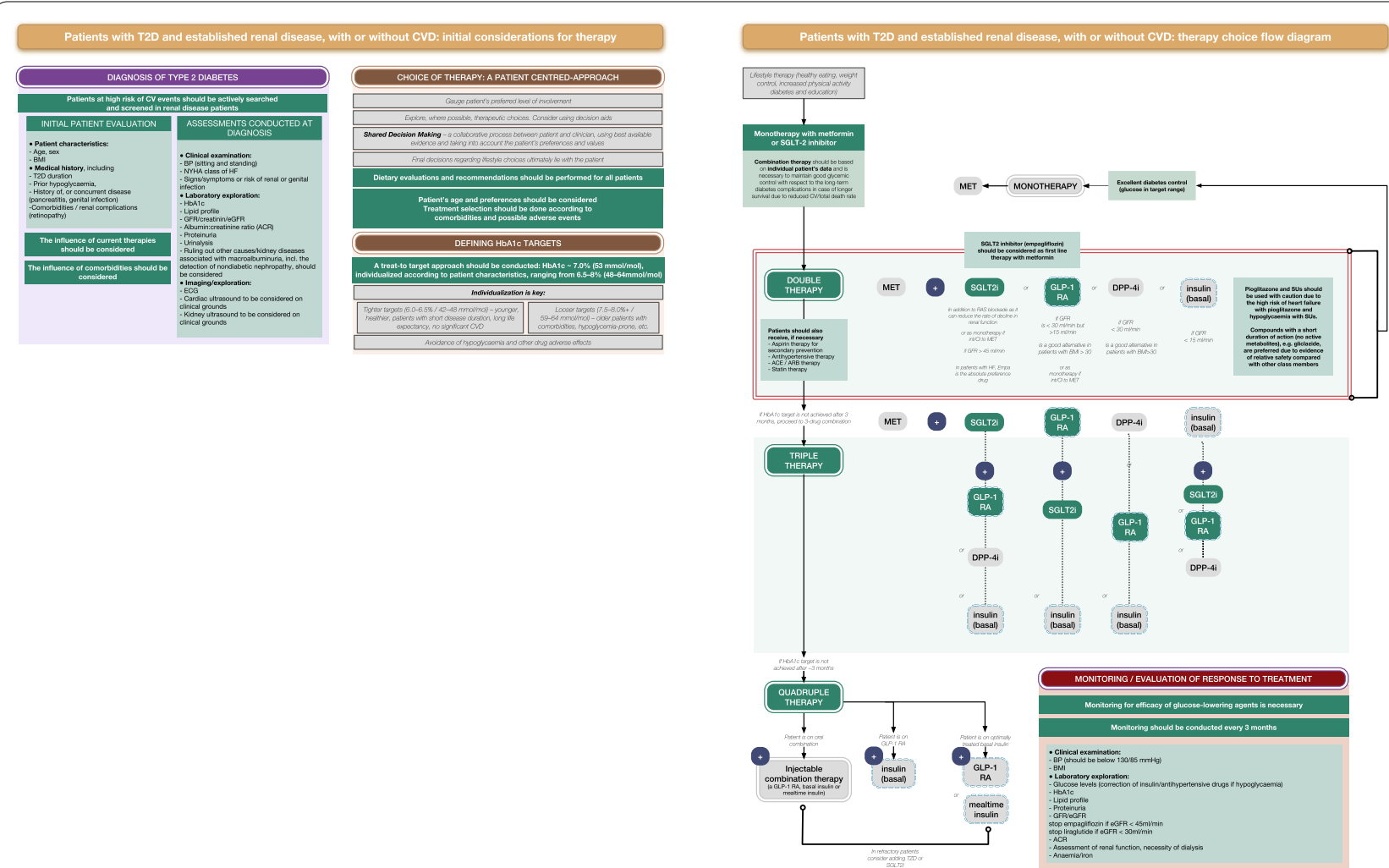

Fig. 2 Treatment algorithm for patients with type 2 diabetes (T2D) and established chronic kidney disease (CKD), with or without cardiovascular disease (CVD): initial considerations for therapy and therapy choice flow diagram. Items in green signify the items of specific focus in these recommendations. Dashed lines indicate injectable therapies. $A C R$ albumin:creatinine ratio, BMI body mass index, BP blood pressure, $C K D$ chronic kidney disease, CVD cardiovascular disease, DPP-4i dipeptidyl peptidase 4 inhibitor, ECG electrocardiogram, GFR glomerular filtration rate, eGFR estimated GFR, DPP-4-i DPP-4 inhibitor, GLP-1 RA glucagon-like peptide 1 receptor agonist, HF heart failure, hypo hypoglycaemia, int/Cl intolerance or contraindication, MET metformin, NYHA New York Heart Association, SGLT2i sodium-glucose co-transporter 2 inhibitor, SU sulfonylurea, T2D type 2 diabetes, TZD thiazolidinedione

emphasised that all agents referred to within these recommendations should be used in accordance with the relevant summary of product characteristics or prescribing information for the country in which they are being prescribed.

\section{Diagnosis/assessment}

The evaluation of all patients should include the following parameters: age, sex, height, weight and body mass index (BMI). The medical history should document the time since diagnosis of T2D, any episodes of prior severe hypoglycaemia and the presence of, or history of, concurrent pancreatitis or genital infection.

For patients with established CKD, any retinopathy, autonomic neuropathy [26], haematological disorders or renal infections should also be ascertained. Patients with established CKD, and at high risk of CV events but with as yet undiagnosed CVD, should be actively screened for the presence of $\mathrm{CV}$ risk factors.
The presence of any other comorbidities and current pharmacological therapies should be determined and taken into consideration when making treatment decisions, to ensure that the patient receives optimally individualised care to achieve the best possible outcome.

A comprehensive investigative work-up is needed to make best-practice treatment decisions. Clinical, laboratory, and, for certain patients, other physiological evaluations should be performed:

- Clinical: blood pressure sitting and standing, and classification of heart failure (HF) according to New York Heart Association functional criteria [27].

- Laboratory:

- HbA1c levels; lipid profile; glomerular filtration rate (GFR)/estimated GFR (eGFR), urinary albumin/ creatinine ratio (UACR) and proteinuria.

- For patients with CKD, urinalysis. 
- Brain natriuretic peptide (BNP)/N-terminal prohormone of BNP (NT-proBNP) should be considered in patients having symptoms or signs of $\mathrm{HF}$.

- Other causes/kidney diseases associated with macroalbuminuria, including the detection of nondiabetic nephropathy, should be ruled out.

- Physiological measurements:

- For patients who are at particular risk of MI, electrocardiogram (ECG) should be performed.

- For patients with CKD, kidney/cardiac ultrasound should be considered depending on clinical need.

\section{Clinical management}

CEEDEG, in common with the EASD/ADA guidelines, recommended a patient-centric approach to treatment to enable the optimal combination of ideal therapy and patient compliance.

\section{Adherence rates and patient education}

Several factors need to be taken into consideration to build on long-term adherence rates and good self-management by patients:

- Therapeutic choices should be explored with the patient, making use of decision aids where rel- evant, and should take place within the context of the patient's priorities, goals and preferred level of involvement.

- Treatment strategies should be kept as simple as possible to reduce the apparent treatment burden, e.g. the use of dual-agent therapies.

- Treatments should be carefully and thoroughly explained to patients on multiple occasions, and reiterated by all practitioners involved in the patient's care.

- The patient's age should also be considered when selecting treatment, taking into account age-related comorbidities and the special repercussions of possible adverse events, such as falls in elderly or frail patients.

- Full dietary evaluation (rather than simple caloric intake) should be performed for all patients.

- The agreed management program should then be implemented and run by clinical specialists and primary care physicians, ideally involving a dietitian and, if needed, a psychologist (Table 2).

\section{Glycaemic control}

CEEDEG recommended a treat-to-target approach based on reducing HbA1c levels to below 7.0\% (53 $\mathrm{mmol} / \mathrm{mol}$ ); however, individualisation is key [28]. For elderly and frail patients with significant CVD or CKD co-morbidities, or who are prone to hypoglycaemia, more relaxed targets

Table 2 Specialities for inter-professional, multidisciplinary team-based type 2 diabetes care for a comprehensive multifactorial risk-reduction strategy in the context of cardiovascular comorbidity

\begin{tabular}{|c|c|}
\hline Speciality & Key functions and areas of responsibility \\
\hline Diabetologist/endocrinologist & $\begin{array}{l}\text { Therapy induction including patient education: explanation of therapy choice, side-effects, complications, acute } \\
\text { emergencies } \\
\text { Sets BP, lipid, HbA1c targets } \\
\text { Trained in cardiology/nephrology/internal medicine }\end{array}$ \\
\hline Internist & $\begin{array}{l}\text { Follow-up care, including monitoring of BP, lipid targets and controls, ECG, echocardiagram imaging } \\
\text { Trained in diabetology (patients with diabetes who are complicated to treat should always be referred to diabe- } \\
\text { tologists/endocrinologists) }\end{array}$ \\
\hline Nephrologist & $\begin{array}{l}\text { Renal function, ACR, BP control } \\
\text { Lipid targets }\end{array}$ \\
\hline Cardiologist & $\begin{array}{l}\text { Essential for CVD and CV risk management } \\
\text { Trained in diabetology }\end{array}$ \\
\hline Nutritionist/dietician & $\begin{array}{l}\text { Dietary counselling at therapy induction } \\
\text { A key figure in patient education together with diabetologist/endocrinologist } \\
\text { Monitoring of glucose control and intake, and body weight } \\
\text { Individual diet plans for weight reduction if needed, and/or long-term weight maintenance }\end{array}$ \\
\hline Nurses & $\begin{array}{l}\text { Education programmes } \\
\text { Individual support } \\
\text { BMI monitoring }\end{array}$ \\
\hline Certified diabetes educator & $\begin{array}{l}\text { Smoking cessation } \\
\text { Diabetes education at treatment induction and for re-enforcement } \\
\text { Education programmes, team work } \\
\text { Consistent and structured education that is crucial for adherence, motivation and minimising barriers to treatment }\end{array}$ \\
\hline
\end{tabular}


in the range of $7.5-8.0+\%(58.5-63.9 \mathrm{mmol} / \mathrm{mol})$ may be applied. This can be tightened to 6.0-6.5\% (42.1$47.5 \mathrm{mmol} / \mathrm{mol}$ ) in younger, healthier patients or those without significant CVD. Overall, it is important to set the target $\mathrm{HbA} 1 \mathrm{c}$ level appropriately for each individual to avoid hypoglycaemia and any other drug-related adverse effects.

\section{Cardiovascular protection}

As discussed in the introduction, $\mathrm{CV}$ mortality remains the main cause of death in this patient group despite recent advances in therapies for T2D. Intensive glycaemic control does not always lead to better CV outcomes [29]; therefore, focusing solely on glucose lowering may not help to address macrovascular complications in T2D. Although the target of modern diabetes therapies in the recent past has been a safe and effective blood glucose reduction [11], recent results of trials dedicated to $\mathrm{CV}$ outcomes clearly demonstrate that innovative diabetic drugs such as empagliflozin and liraglutide can add significant benefit to outcomes for patients with T2D in terms of a reduction in CV death [23, 30-32]. These important clinical results have led to a new duality paradigm for T2D treatment, whereby both the improvement of glycaemic control and the reduction of CV morbidity and mortality become an integral part of the treatment of T2D. Therefore, $\mathrm{CV}$ risk and protection should always be considered when determining therapeutic regimens for patients with T2D.

\section{Type 2 diabetes therapeutic regimens} Monotherapy

Although monotherapy with metformin is commonly used in patients with no CV comorbidities, the early combining of metformin therapy together with agents that reduce $\mathrm{CV}$ risk should be preferred in patients with T2D and established CVD.

Progressing patients from mono- to combination therapy should be considered on an individual basis, depending on the patient's investigation data, and is recommended to achieve good glycaemic control and better $\mathrm{CV}$ and renoprotective outcomes.

\section{Combination therapy}

Current glucose-lowering therapies comprise six classes, each with differing combinations of attributes over and above decreasing $\mathrm{HbA1c}$, such as effects on CV risk, renal outcomes, blood pressure and weight. Suitability for use in the presence of nephropathy should be considered when choosing agents for multiple combinations (Table 3).

\section{Dual therapy}

The choice of agent for initial combination with metformin can be streamlined on the basis of patient comorbidities and characteristics.

\section{SGLT2 inhibitors}

For patients with T2D and CVD, sodium-glucose cotransporter 2 (SGLT2) inhibitors should be considered for use after metformin monotherapy in those with a GFR $>60 \mathrm{ml} / \mathrm{min}$ (or $>45 \mathrm{ml} / \mathrm{min}$ or above in countries where this is the indicated threshold for empagliflozin/ canagliflozin prescribing).

Current evidence from the EMPA-REG OUTCOME ${ }^{\circledR}$ trial showed that empagliflozin significantly reduced the time to the first occurrence of the primary composite endpoint of 3-point major adverse cardiovascular events (3-P MACE): CV death, non-fatal MI or non-fatal stroke (HR: 0.86; 95\% CI 0.74-0.99) [21, 30, 33, 34]. The primary endpoint improvement was mostly driven by a $38 \%$ relative risk reduction (RRR) in the key outcome of CV mortality (HR 0.62; 95\% CI 0.49-0.77). Hospitalisation for HF, a defined secondary outcome, was also significantly lower in the empagliflozin group compared with placebo (HR 0.65; 95\% CI $0.50-0.85 ; p<0.002)$, likewise, there was a significant lowering of all-cause mortality with the addition of empagliflozin to standard of care (HR 0.68, 95\% CI 0.57$0.82 ; p<0.001)$. This SGLT2 inhibitor should therefore be preferentially chosen for patients at high risk of $\mathrm{CV}$ events [33].

For patients with T2D and CKD, empagliflozin was recommended in early combination with metformin and renin-angiotensin system (RAS) blockade, as it can reduce the rate of renal decline. Incidence of or worsening nephropathy occurred in fewer patients in the empagliflozin group than in the placebo group (HR 0.61; 95\% CI $0.53-0.70)$. In patients treated with empagliflozin compared with placebo there was a RRR of the doubling of serum creatinine levels of $44 \%$, and a $55 \%$ RRR of renal-replacement therapy being initiated [30].

Owing to the documented $\mathrm{CV}$ benefits mentioned above, empagliflozin should be considered as the drug of preference for patients with T2D and CKD who also have established CVD.

Empagliflozin may also be used as a monotherapy if the patient is intolerant to metformin or if metformin is contraindicated.

\section{GLP-1 receptor agonists}

Glucagon-like peptide 1 (GLP-1) receptor agonists (preferentially liraglutide) should be considered in patients with a GFR below $60 \mathrm{ml} / \mathrm{min}$ but greater than $30 \mathrm{ml} /$ min. The results of the LEADER ${ }^{\circledR}$ CVOT of liraglutide in patients with T2D and at high risk of $\mathrm{CV}$ events showed lower CV-related and all-cause mortalities in patients treated with liraglutide compared with placebo (HR 0.78; 95\% CI 0.66-0.93 and HR 0.85; 95\% CI 0.74-0.97, respectively) [23]. These agents are also recommended 
Table 3 Current glucose-lowering therapies and their key attributes. Adapted from the SGED/SSED guidelines [13, 15], except where indicated

\begin{tabular}{|c|c|c|c|c|}
\hline Class & Beneficial effect on CV outcomes & Beneficial effect on $\mathrm{HbA} 1 \mathrm{c}$ levels & Effect on weight & Hypoglycaemic risk \\
\hline Metformin (oral) & Moderate (long-term) & Moderate & Moderate decrease & Neutral \\
\hline \multicolumn{5}{|c|}{ SGLT2 inhibitors (oral) } \\
\hline Empagliflozin ${ }^{\mathrm{e}}$ & High (empagliflozin and canagliflozin) & Moderate to high & High decrease & Neutral \\
\hline \multicolumn{5}{|l|}{ Canagliflozin } \\
\hline \multicolumn{5}{|l|}{ Dapagliflozin } \\
\hline \multicolumn{5}{|c|}{ GLP-1 receptor agonists (injection) } \\
\hline Liraglutide & High (liraglutide and semaglutide) & High & Very high decrease & Neutral \\
\hline \multicolumn{5}{|l|}{ Semaglutide } \\
\hline \multicolumn{5}{|l|}{ Exenatide } \\
\hline \multicolumn{5}{|l|}{ Exenatide LAR } \\
\hline \multicolumn{5}{|l|}{ Dulaglutide ${ }^{a}$} \\
\hline \multicolumn{5}{|c|}{ DPP-4 inhibitors (oral) } \\
\hline Sitagliptin ${ }^{\mathrm{e}}$ & Neutral & Moderate & Neutral & Neutral \\
\hline \multicolumn{5}{|l|}{ Alogliptine } \\
\hline \multicolumn{5}{|l|}{ Linagliptin $^{e}$} \\
\hline \multicolumn{5}{|l|}{ Saxagliptin } \\
\hline \multicolumn{5}{|l|}{ Vildagliptin ${ }^{\mathrm{e}}$} \\
\hline \multicolumn{5}{|l|}{ Insulins (injection) } \\
\hline Insulin degludec & Neutral & High & Neutral & High \\
\hline \multicolumn{5}{|l|}{ Insulin glargine } \\
\hline \multicolumn{5}{|l|}{ TZDs (oral) } \\
\hline Pioglitazone & High? ${ }^{b}$ & Moderate? ${ }^{c}$ & Increase ${ }^{d}$ & \\
\hline \multicolumn{5}{|l|}{ SUs (oral) } \\
\hline Gliclazide & Neutral & Moderate & Neutral & Moderate \\
\hline Glimepiride & & & & \\
\hline
\end{tabular}

Agents in italics have a higher level of evidence for reduction of micro- and macrovascular complications and mortality or fewer side-effects

CV cardiovascular, DPP-4 dipeptidyl peptidase 4, GLP-1 glucagon-like peptide 1, LAR long-acting release, SGLT2 sodium-glucose co-transporter 2, SU sulfonylurea, TZD thiazolidinedione

a A meta-analysis of the CV safety of dulaglutide in patients with T2D [52]

b Astudy that predates the CVOT mandate demonstrated significant reduction in a CV composite outcome. The study was a post hoc analysis of a prospective clinical trial $[41,53]$

c A double-blind, randomised trial that compared pioglitazone with metformin as monotherapies found that the HbA1c reduction was similar between the two drugs $[42,54]$

d An observational prescription-event monitoring study that showed treatment with pioglitazone was associated with a low incidence of hypoglycaemia [43, 55]

e Also available in combination with metformin

for patients with a BMI > 30, owing to their documented benefits in weight reduction. GLP-1 receptor agonists may also be used as a single agent in patients intolerant to metformin.

\section{DPP-4 inhibitors}

CVOTs of the dipeptidyl peptidase 4 (DPP-4) inhibitors saxagliptin, alogliptin and sitagliptin have shown neutral results in which neither an increase nor a decrease was seen in the rate of ischaemic events in patients treated with these agents when compared with placebo, although the rate of hospitalisation for HF was increased for saxagliptin [35-37]. For patients who are unsuitable for either an SGLT2 inhibitor or a GLP-1 receptor agonist, such as those with an eGFR below $60 \mathrm{ml} / \mathrm{min}(30 \mathrm{ml} / \mathrm{min}$ for patients with CKD), DPP-4 inhibitors (oral) may be considered.

\section{Insulin}

Basal insulin injections are an option for all patients However, it is recommended that their early use is restricted to those patients with a GFR below $60 \mathrm{ml} / \mathrm{min}$ ( $15 \mathrm{ml} / \mathrm{min}$ for patients with CKD) and who cannot be prescribed any of the aforementioned agents. Otherwise, this treatment option should be reserved for later use. 


\section{Other type 2 diabetes treatment agents}

Pioglitazone and sulfonylureas (SUs) should be used with caution in all patients, owing to the high risk of congestive HF in the former and hypoglycaemia in the latter of these agents. Where prescribing these classes is necessary, e.g. for financial/reimbursement reasons, compounds with a short duration of action (no active metabolites), such as gliclazide, are preferred, owing to the evidence of relative safety compared with other class members.

\section{Triple therapy}

If, after 3 months of dual combination therapy, the HbA1c target is not achieved, the addition of a third therapeutic agent should be considered as second-line combination therapy. Here, the choice of additional agent should largely depend on responses to the existing combination, as well as on the patient's co-morbidities.

For all patients who are already taking metformin plus an SGLT2 inhibitor for its CV risk-reduction benefits, the recommended third agents are, in order of preference, a GLP-1 receptor agonist, a DPP-4 inhibitor or basal insulin. CEEDEG recommended that patients who do not show a decrease in HbA1c level from treatment with empagliflozin should not be simply switched to a GLP-1 receptor agonist, owing to the documented important cardio- and renoprotective effects of empagliflozin.

The agents that are of most benefit to patients with T2D and CVD who are already being treated with metformin and a GLP-1 receptor agonist are either an SGLT2 inhibitor or basal insulin.

For those patients who received a DPP-4 inhibitor with metformin in the first instance, then either the DPP-4 inhibitor should be replaced by a long-acting GLP-1 receptor agonist, or a basal insulin or gliclazide should be prescribed. For patients who received basal insulin with metformin, add an SGLT2 inhibitor, a GLP-1 receptor agonist or a DPP-4 inhibitor, depending on the GFR.

A quadruple combination should be initiated if, after a further 3 months of triple combination therapy, the patient has still not achieved their individual target HbA1c level. For those patients who are taking oral therapies, an injectable therapy should be added: a GLP-1 receptor agonist, basal insulin or mealtime insulin. If the patient is receiving a GLP-1 receptor agonist, then basal insulin should be the next agent. If the patient is already on optimally treated basal insulin, then either a GLP-1 receptor agonist or mealtime insulin should be added, depending on whether they are already taking a GLP-1 receptor agonist. If patients remain refractory to treatment, then consider adding a thiazolidinedione (TZD) or an SGLT2 inhibitor, also depending on the existing therapeutic agents that the patient is receiving.

\section{Monitoring/evaluation of response to treatment}

As suggested above, to determine the efficacy of glucoselowering treatments, and to monitor changes in $\mathrm{CV}$ risk factors, regular monitoring of the patient should be conducted at 3-monthly intervals. The parameters that should be evaluated are similar to those for initial assessment, and should remain comprehensive to manage both glucose levels and CV risk.

Clinical examination should include blood pressure and BMI. The laboratory tests should ascertain glucose levels to allow for correction of insulin/anti-hypertensive drugs if the patient has been experiencing hypoglycaemia. Laboratory tests should also measure HbA1c level, lipid profile, and proteinuria, GFR/eGFR and UACR.

The SGLT2 inhibitor empagliflozin should be withdrawn if the eGFR has reduced to below $45 \mathrm{ml} / \mathrm{min}$ as indicated; however, data from clinical studies show that benefits may still be seen in patients down to an eGFR of $30 \mathrm{ml} / \mathrm{min}$ [30, 33]. The GLP-1 receptor agonist liraglutide should also be withdrawn when a minimum eGFR of $30 \mathrm{ml} / \mathrm{min}$ is reached.

A repeat ECG should be performed as part of the follow-up to monitor any changes in CV status.

\section{Cardiac/lipid control}

In addition to glucose-lowering agents, patients should also receive an anti-platelet aggregation agent, betablocker, angiotensin-converting enzyme (ACE) inhibitor, angiotensin receptor blocker (ARB) and statin therapies if indicated.

\section{Special prescribing considerations}

Although basal and other insulins have been somewhat superseded by the new generation of anti-hyperglycaemic drugs, they should not be excluded where needed. When prescribing insulins, however, the latest evidence should be considered, which suggests that insulin is best used alongside more modern drugs. Insulin has good glucose-lowering effects, but can lead to hypoglycaemia if not carefully prescribed according to the patient's lifestyle; therefore, its therapeutic effect should be carefully evaluated. For patients who are receiving other glucoselowering agents that may offer other benefits, such as $\mathrm{CV}$ and renal protection, but who are not achieving their target HbA1c levels, insulin in combination with more modern drugs may enable them to control both aspects of their condition. CEEDEG felt that the evidence for the use of insulin as a monotherapy does not warrant its use in this way, especially for the older, short-acting forms.

\section{Elderly patients}

Patients in the upper age ranges (75 years and older) are highly variable in terms of individual fitness and general 
lifestyles. Although care should be taken to avoid hypoglycaemia and its associated increased risk of falls when treating frail elderly patients with T2D and CVD, it should be taken into account that the maximum CV benefits derived from the SGLT2 inhibitor empagliflozin in the EMPA-REG OUTCOME ${ }^{\circledR}$ study were seen among the older participants, and this population is also more likely to suffer from CV and renal comorbidities. Preventative measures should therefore be taken to avoid hypovolaemia when prescribing empagliflozin in this patient group. In the $\mathrm{LEADER}^{\circledR}$ study of liraglutide, however, patients aged over 60 years experienced fewer $\mathrm{CV}$ events in the placebo arm than in the treatment arm [22, 23].

As with all other therapies, therefore, patient preference should be taken together with the medical history when choosing an appropriate agent or agents.

\section{Class effect}

No strong evidence has yet been found for a class effect regarding positive $\mathrm{CV}$ outcomes of anti-diabetic agents (Table 4 and Additional file 4: Table S1), although overall, no increased CV risk has been observed [10]. For example, CVOTs for GLP-1 receptor agonists and DPP-4 inhibitors have shown mixed results depending on the individual drug [23, 25, 35-38]. In the SGLT2 inhibitor class, although the EMPA-REG OUTCOME ${ }^{\circledR}$ study and CANVAS program differ (for example by study design and the pharmacological characteristics of the drugs), the results of both trials showed a significant reduction on the composite endpoint (3P-MACE); however, individual components of 3P-MACE and key secondary outcomes differed greatly $[33,39]$. In the EMPA-REG OUTCOME $^{\circledR}$ study, CV death had a relative risk reduction of $38 \%$ (95\% CI 0.49-0.77), whereas in the CANVAS Program CV death was not significantly reduced $(13 \%$ RRR, 95\% CI 0.72-1.06). Additionally, in the EMPA-REG OUTCOME $^{\circledR}$ study the key secondary outcomes of allcause mortality (RRR 32\%, 95\% CI 0.57-0.82, p < 0.001), HHF (RRR 35\%, 95\% CI 0.50-0.85, p < 0.001) and the composite renal outcome (RRR 46\%, 95\% CI 0.31-0.85, $\mathrm{p}<0.001)$ all showed a statistically significant benefit when adding empagliflozin versus placebo to standard of care [33]. By contrast, in the CANVAS Program none of the secondary outcomes showed a statistical benefit [39]. This is in part owing to all-cause mortality not being significantly reduced in the CANVAS Program (13\% RRR, 95\% CI 0.74-1.01) after which all other secondary outcomes analysed in the sequential hypothesis testing plan can only be interpreted as exploratory, such as HHF (33\% RRR, 95\% CI 0.52-0.87) and the composite renal outcome (RRR 40\%, 95\%CI 0.47-0.77). In contrast, EMPAREG OUTCOME ${ }^{\circledR}$ was powered sufficiently to achieve significance in both HHF (RRR 35\%, 95\% CI 0.5-0.85,
Table 4 Table of 3-point MACE for CVOT studies to date. Adapted from [39, 50, 51]

\begin{tabular}{|c|c|c|c|}
\hline & Antidiabetic drug & $\begin{array}{l}\text { 3P-MACE hazard } \\
\text { ratio (HR) }\end{array}$ & $p$ value \\
\hline PROactive & Pioglitazone & $\begin{array}{r}0.84(95 \% \mathrm{Cl} \\
0.72-0.98)\end{array}$ & 0.02 \\
\hline ORIGIN & Insulin glargine & $\begin{array}{r}1.02(95 \% \mathrm{Cl} \\
0.94-1.11)\end{array}$ & NS \\
\hline SAVOR & Saxagliptin & $\begin{array}{r}1.00(95 \% \mathrm{Cl} \\
0.89-1.12)\end{array}$ & NS \\
\hline EXAMINE & Alogliptin & $\begin{array}{r}0.96(95 \% \mathrm{Cl} \\
0.80-1.15)\end{array}$ & NS \\
\hline ELIXA & Lixisenatide & $\begin{array}{r}1.02(95 \% \mathrm{Cl} \\
0.89-1.17)\end{array}$ & NS \\
\hline TECOS & Sitagliptin & $\begin{array}{r}0.98(95 \% \mathrm{Cl} \\
0.89-1.08)\end{array}$ & NS \\
\hline $\begin{array}{l}\text { EMPA-REG } \\
\text { OUTCOME }^{\circledR}\end{array}$ & Empagliflozin & $\begin{array}{r}0.86(95 \% \mathrm{Cl} \\
0.74-0.99)\end{array}$ & 0.038 \\
\hline LEADER $^{\circledR}$ & Liraglutide & $\begin{array}{r}0.87(95 \% \mathrm{Cl} \\
0.78-0.97)\end{array}$ & 0.01 \\
\hline SUSTAIN $^{\mathrm{TM}}-6$ & Semaglutide & $\begin{array}{r}0.74(95 \% \mathrm{Cl} \\
0.58-0.95)\end{array}$ & $<0.001^{\mathrm{a}}$ \\
\hline CANVAS-program & Canagliflozin & $\begin{array}{r}0.86(95 \% \mathrm{Cl} \\
0.75-0.97)\end{array}$ & 0.02 \\
\hline
\end{tabular}

This is not a head-to-head comparison

CVOT cardiovascular outcomes trial, MACE major adverse cardiovascular events (cardiovascular death, non-fatal myocardial infarction or non-fatal stroke), NS not significant

a SUSTAIN ${ }^{\mathrm{TM}}-6$ was a non-inferiority study, and testing for superiority was not a pre-specified endpoint

$\mathrm{p}<0.001$ ) and the composite renal outcome (RRR 46\%, 5\% CI 0.31-0.85, p < 0.001) [30, 33, 39]. An additional difference between SGLT2 inhibitors is the observation that there was an increased signal for lower limb amputations related to canagliflozin use in the CANVAS studies, an outcome that, although observed at a higher rate in patients with diabetes than in the general population, has not been observed in any of the empagliflozin or dapagliflozin studies to date [39-44].

\section{Real world evidence studies}

Currently, some agents such as exenatide and dapagliflozin only have CV data from meta-analyses or observational studies [45, 46]. Recently published results from the real-world evidence observational study CVD-REAL, in which the risk of HHF in individuals with T2D who had been newly initiated on SGLT2 inhibitors (canagliflozin, dapagliflozin or empagliflozin) was compared to other glucose-lowering drugs (oGLD), have shown similar trends for risk reductions in HF and all-cause mortality associated with SGLT2 inhibitor use [47].This held true for all six countries involved in the study, despite differences in the background treatment and the use of different SGLT2 inhibitors in the US and Europe. Furthermore, 
as both HF and the subclinical forms of HF are amongst the earliest vascular complications seen when following up diabetic patients who do not have CVD at baseline [48], it may be suggested that these patients in CVDREAL benefited from the early use of SGLT2 inhibitors. Of note, there were clear differences between the outcomes in the propensity-matched CVD-REAL and the double-blind, randomised, placebo-controlled, CANVAS Program cohorts, despite canagliflozin comprising the largest overall component of the SGLT2 inhibitors in the CVD-REAL study [39, 47]. For example, in the CANVAS Program, although the combined primary endpoint of 3P-MACE was reduced by $14 \%$, there was no significant reduction in all-cause mortality, yet in the CVD-REAL US cohort, where $75 \%$ of patients were receiving canagliflozin, mortality was reduced in the SGLT2 inhibitor group by $62 \%$ (HR $0.38,95 \%$ CI $0.29-0.50$ ) [39, 47, 49]. This is most likely to be as a result of the differing methodologies of the two studies and known limitations of using retrospective data. We therefore feel that although well-performed observational studies showing the same trend can lend support to results that have been obtained from RCTs, only prospective well-performed CVOTs, in which strict study criteria, equalisation of baseline characteristics, and elimination of observer bias, can offer robust evidence of $\mathrm{CV}$ benefit. Until the results of the dapagliflozin DECLARE CVOT study become available in 2018, we cannot be confident in a class effect for the SGLT2 inhibitor class. We currently advise that when using the treatment algorithms physicians should continue to evaluate each of the members of any of the classes on the basis of their individual efficacy and safety data $[23,33,35-38]$.

\section{Multidisciplinary management}

A key aspect of therapy for patients with T2D and comorbidities is the provision of a multidisciplinary team, the members of which contribute in complementary ways to improving patient outcomes. CEEDEG recommended the specialities that should be included in the multidisciplinary team and suggested their key functions and responsibilities within the team (Table 3).

\section{Discussion}

Patient outcomes are best served by the rapid implementation of emerging superior therapies, putting pressure on clinical guideline groups to continuously update their outputs. The addition of interim recommendation publications to be used in tandem with existing guidelines will enable a swifter response to a continuously changing therapeutic landscape. Recent data from CVOT studies of anti-diabetes drugs, and the anticipation of a stream of further CVOT results becoming available in the future, mean that the CEEDEG objective of providing regular companion recommendations is a welcome initiative.

By following a structured process, unbiased consensus treatment algorithms were derived that take into consideration data from CVOTs on the $\mathrm{CV}$ and renoprotective aspects of newer anti-diabetic agents and establish their place in the therapeutic landscape. This initiative interprets the data in such a way as to enable prescribing physicians to more easily determine the optimum treatment regimen for both the medical and lifestyle needs of their patients with T2D and CVD, or with T2D and CKD with or without CVD.

\section{Additional files}

Additional file 1. Round 1 questionnaire.

Additional file 2. Initial recommendation scoring.

Additional file 3. Final recommendation scoring.

Additional file 4: Table S1. Selected outcomes from SGLT2 inhibitor CVOTs.

\section{Abbreviations}

ACE: angiotensin-converting enzyme; ACR: albumin:creatinine ratio; ADA: American Diabetes Association; ARB: angiotensin receptor blocker; BMI: body mass index; BNP: brain natriuretic peptide; BP: blood pressure; CEEDEG: Central and Eastern European Diabetes Expert Group; Cl: confidence interval; CKD: chronic kidney disease; CV: cardiovascular; CVD: cardiovascular disease; CVOT: cardiovascular outcomes trial; DPP-4: dipeptidyl peptidase 4; EASD: European Association for the Study of Diabetes; ECG: electrocardiogram; ECHO: echocardiogram; eGFR: estimated glomerular filtration rate; EMA: European Medicines Agency; ESC: European Society of Cardiology; FDA: US Food and Drug Administration; GFR: glomerular filtration rate; GLP-1: glucagon-like peptide 1; HbA1c: glycated haemoglobin A1c; HF: heart failure; HR: hazard ratio; LAR: long-acting release; MACE: major adverse cardiovascular events; MI: myocardial infarction; NS: not significant; NT-proBNP: N-terminal prohormone of BNP; ÖDG: Austrian Society for Diabetes; RAS: renin-angiotensin system; RRR: relative risk reduction; SGLT2: sodium-glucose co-transporter 2; SSED/SGED: Swiss Society of Endocrinology and Diabetes; SUs: sulfonylureas; T2D: type 2 diabetes; TZD: thiazolidinedione; UACR: urinary albumin/creatinine ratio.

\section{Authors' contributions}

All authors participated in the whole Delphi process. GS, RL and MP moderated discussions during the face-to-face meeting. All authors contributed to the content and critical review of the manuscript and algorithms. All authors read and approved the final manuscript.

\section{Author details}

${ }^{1}$ Department of Medicine I, Rudolfstitung Hospital, Vienna, Austria. ${ }^{2}$ Division of Endocrinology and Diabetes of the University Hospital, Zurich, Switzerland. ${ }^{3}$ Diabetes Centre, Charles University and General Faculty Hospital, Prague, Czech Republic. ${ }^{4}$ Department of Diabetology and Internal Medicine, Warsaw Medical University, Warsaw, Poland. ${ }^{5}$ Faculty of Internal Medicine, University of Latvia, Riga, Latvia. ${ }^{6} 5$ th Medical Department, Wilhelminenspital, Vienna, Austria. ${ }^{7}$ Department of Endocrinology, Diabetes and Metabolic Diseases, University Medical Centre, Ljubljana, Slovenia. ${ }^{8}$ Chaim Sheba Medical Centre, Tel Hashomer, Israel. ${ }^{9}$ Department of Medicine, Semmelweis University, Budapest, Hungary. ${ }^{10}$ National Institute of Endocrinology and Diabetology, Lubochna, Slovakia. ${ }^{11}$ Endocrinology Research Centre, Moscow, Russia. ${ }^{12}$ Department of Endocrinology and Metabolic Diseases, Vuk Vrhovac University Clinic for Diabetes, Endocrinology and Metabolic Diseases, Merkur University Hospital, School of Medicine, University of Zagreb, Zagreb, Croatia. ${ }^{13}$ Clinical Centre of Endocrinology, Medical University, Sofia, Bulgaria. 


\section{Acknowledgements}

Editorial support was provided by Fortis Pharma Communications, with financial support by Boehringer Ingelheim (BI). The opinions expressed are entirely the authors' own and the only involvement of BI was to have sight of the manuscript for accuracy.

\section{Competing interests}

GS has previously received research grants and honoraria for speaking from Abbot, Amgen, Andromeda, AstraZeneca, Bayer, Boehringer Ingelheim, BMS, DeveloGen, Eli Lilly, GSK, Janssen, Merck, MSD, Novartis, Novo Nordisk, Pfizer, Roche, Sanofi-Aventis, Serono, Servier and Takeda, and has served as principal investigator in more than 40 studies. RL has previously received honoraria for speaking and consultancy from Boehringer Ingelheim, MSD, Astra-Zeneca, Novo-Nordisk, Sanofi, Eli-Lilly, Medtronic and Roche. MP has previously received honoraria for speaking and consultancy from Abbott, AstraZeneca, Boehringer Ingelheim, Dexcom, Eli Lilly, Medtronic, Novo Nordisk, Roche, Sanofi, Servier and Takeda.

AJ has previously received honoraria for speaking and consultancy from Amgen, AstraZeneca, Boehringer Ingelheim, Merck, Medtronic, MSD, Novo Nordisk, Sanofi. LSD has previously received honoraria for speaking and consultancy from Abbott, Amgen, AstraZeneca, Boehringer Ingelheim, Eli Lilly, Merck, MSD, Novo Nordisk, Sanofi, Servier and Takeda.

EM has previously received honor for speaking and consultation from Abbot, AstraZeneca, Boehringer Ingelheim, Eli Lilly, Janssen, Medtronick, MSD, Novartis, Novo Nordisk, Pfizer, Roche, Sanofi-Aventis, Servier and Takeda, and has served as principal investigator in more than 20 studies.

MVS has previously received honoraria for speaking and consultancy from Boehringer Ingelheim, MSD, Astra-Zeneca, Novo-Nordisk, Sanofi, Eli-Lilly, Servier.

TT has previously received honoraria for speaking and consultancy from Boehringer Ingelheim, MSD, AstraZeneca, Novo Nordisk, Sanofi, Eli Lilly, Novartis, Servier, Mylan, Worwag.

PF has previously received research grants and honoraria for speaking and consultancy from AstraZeneca, Boehringer Ingelheim, EliLilly, MSD, Novartis, Novo Nordisk, Sanofi, Servier and Takeda.

The authors declare that they have no competing interests.

\section{Availability of data and materials}

All data generated or analysed during this study are included in this published article (and its additional information files).

\section{Consent for publication}

Not applicable.

\section{Ethics approval and consent to participate}

Not applicable.

\section{Funding}

Organisation of the meeting and editorial support was provided with Boehringer Ingelheim with the support of the medical communication agency Fortis Pharma communications.

\section{Publisher's Note}

Springer Nature remains neutral with regard to jurisdictional claims in published maps and institutional affiliations.

Received: 17 July 2017 Accepted: 15 October 2017

Published online: 23 October 2017

\section{References}

1. DeFronzo RA, Ferrannini E, Groop L, Henry RR, Herman WH, Holst JJ, Hu FB, Kahn CR, Raz I, Shulman Gl, et al. Type 2 diabetes mellitus. Nat Rev Dis Primers. 2015:1:15019.

2. Rao Kondapally Seshasai S, Thompson A, Di Angelantonio E, Gao P, Sarwar N, Whincup PH, Mukamal KJ, Gillum RF, Holme I, et al. Diabetes mellitus, fasting glucose, and risk of cause-specific death. N Engl J Med. 2011;364:829-41.

3. Skyler JS, Bergenstal R, Bonow RO, Buse J, Deedwania P, Gale EA, Howard BV, Kirkman MS, Kosiborod M, Reaven P, et al. Intensive glycemic control and the prevention of cardiovascular events: implications of the ACCORD, ADVANCE, and VA diabetes trials: a position statement of the American Diabetes Association and a scientific statement of the American College of Cardiology Foundation and the American Heart Association. Diabetes Care. 2009;32:187-92.

4. Johansen OE. Interpretation of cardiovascular outcome trials in type 2 diabetes needs a multiaxial approach. World J Diabetes. 2015;6:1092-6.

5. Nissen SE, Wolski K. Effect of rosiglitazone on the risk of myocardial infarction and death from cardiovascular causes. N Engl J Med. 2007;356:2457-71.

6. Chen X, Yang L, Zhai SD. Risk of cardiovascular disease and all-cause mortality among diabetic patients prescribed rosiglitazone or pioglitazone: a meta-analysis of retrospective cohort studies. Chin Med J. 2012;125:4301-6.

7. Florez H, Reaven PD, Bahn G, Moritz T, Warren S, Marks J, Reda D, Duckworth W, Abraira C, Hayward R, et al. Rosiglitazone treatment and cardiovascular disease in the Veterans Affairs Diabetes Trial. Diabetes Obes Metab. 2015;17:949-55.

8. $\mathrm{CMPH}$. Guideline on Clinical investigation of medicinal products in the treatment or prevention of diabetes mellitus. Use CFMPfH, editor. London; 2012.

9. FDA. Guidance for industry. FDA, editor. 2008. p. 1-8.

10. Schnell O, Ryden L, Standl E, Ceriello A, Group CES. Current perspectives on cardiovascular outcome trials in diabetes. Cardiovasc Diabetol. 2016;15:139.

11. Inzucchi SE, Bergenstal RM, Buse JB, Diamant M, Ferrannini E, Nauck M, Peters AL, Tsapas A, Wender R, Matthews DR. Management of hyperglycaemia in type 2 diabetes, 2015: a patient-centred approach. Update to a position statement of the American Diabetes Association and the European Association for the Study of Diabetes. Diabetologia. 2015;58:429-42.

12. Qaseem A, Barry MJ, Humphrey LL, Forciea MA, Clinical Guidelines Committee of the American College of P. Oral pharmacologic treatment of type 2 diabetes mellitus: a clinical practice guideline update from the American College of Physicians. Ann Intern Med. 2017;166:279-90.

13. Ponikowski P, Voors AA, Anker SD, Bueno H, Cleland JG, Coats AJ, Falk V, Gonzalez-Juanatey JR, Harjola VP, Jankowska EA, et al. 2016 ESC guidelines for the diagnosis and treatment of acute and chronic heart failure: the Task Force for the diagnosis and treatment of acute and chronic heart failure of the European Society of Cardiology (ESC) developed with the special contribution of the Heart Failure Association (HFA) of the ESC. Eur Heart J. 2016;37:2129-200.

14. American Diabetes A. Standards of medical care in diabetes-2017 abridged for primary care providers. Clin Diabetes. 2017;35:5-26.

15. Lehmann R, Bianda T, Brändle M, Czock A, Egli M, Phillippe J, Settler C, Thalmann S, Weng T. Recommandation SSED/SGED: Mesures visant contrôle de la glycémie chez les patients atteints de diabète sucré de type 2 . SSED Gdtdl, editor. Switzerland; 2016.

16. Jermendy G, Gaál Z, Gerő L, Hidvég IT, Kempler P, Winkler G, Wittmann I. Egészségügyi szakmai irányelv—a diabetes mellitus kórismézéséről, a cukorbetegek antihyperglykaemiás kezeléséről és gondozásáról felnőttkorban. Diabetol Hung. 2017;25:3-77.

17. Martinka E, Uličiansky V, Mokáň M, Tkáč I, Galajda P, Schroner Z. Consensual therapeutic algorithm for type 2 diabetes mellitus. Interná Med. 2016;16:301-10.

18. Dedov II, Shestakova MV, Mayorov AY. Standards of specialized diabetes care: 8th edition. Diabetes Mellitus. 2017;20:1-121.

19. ODG. Diabetes mellitus_Anleitungen für die Praxis. Überarbeitete und erweiterte Fassung 2016. Wiener Klinische Wochenschrift. 2016;128:S37-228.

20. Holliday C, Robotin M. The Delphi process: a solution for reviewing novel grant applications. Int J Gen Med. 2010;3:225-30.

21. Fitchett D, Zinman B, Wanner C, Lachin JM, Hantel S, Salsali A, Johansen OE, Woerle HJ, Broedl UC, Inzucchi SE. Heart failure outcomes with empagliflozin in patients with type 2 diabetes at high cardiovascular risk: results of the EMPA-REG OUTCOME ${ }^{\circledR}$ trial. Eur Heart J. 2016;37:1526-34.

22. Margulies KB, Hernandez AF, Redfield MM, Givertz MM, Oliveira GH, Cole R, Mann DL, Whellan DJ, Kiernan MS, Felker GM, et al. Effects of 
liraglutide on clinical stability among patients with advanced heart failure and reduced ejection fraction: a randomized clinical trial. JAMA. 2016;316:500-8

23. Marso SP, Daniels GH, Brown-Frandsen K, Kristensen P, Mann JF, Nauck MA, Nissen SE, Pocock S, Poulter NR, Ravn LS, et al. Liraglutide and cardiovascular outcomes in type 2 diabetes. N Engl J Med. 2016;375:311-22.

24. Zinman B, Inzucchi SE, Lachin JM, Wanner C, Ferrari R, Fitchett D, Bluhmki E, Hantel S, Kempthorne-Rawson J, Newman J, et al. Rationale, design, and baseline characteristics of a randomized, placebo-controlled cardiovascular outcome trial of empagliflozin (EMPA-REG OUTCOME). Cardiovasc Diabetol. 2014;13:102.

25. Marso SP, Bain SC, Consoli A, Eliaschewitz FG, Jódar E, Leiter LA, Lingvay I, Rosenstock J, Seufert J, Warren ML, et al. Semaglutide and cardiovascular outcomes in patients with type 2 diabetes. N Engl J Med. 2016:375:1834-44.

26. Tahrani AA, Dubb K, Raymond NT, Begum S, Altaf QA, Sadiqi H, Piya MK, Stevens MJ. Cardiac autonomic neuropathy predicts renal function decline in patients with type 2 diabetes: a cohort study. Diabetologia. 2014;57:1249-56.

27. Association TCCotNYH. Nomenclature and criteria for diagnosis of diseases of the heart and great vessels. 9th ed. Boston: Little, Brown \& Co; 1994. p. 253-6.

28. Wang P, Huang R, Lu S, Xia W, Sun H, Sun J, Cai R, Wang S. HbA1c below $7 \%$ as the goal of glucose control fails to maximize the cardiovascular benefits: a meta-analysis. Cardiovasc Diabetol. 2015;14:124

29. Control G, Turnbull FM, Abraira C, Anderson RJ, Byington RP, Chalmers JP, Duckworth WC, Evans GW, Gerstein HC, Holman RR, et al. Intensive glucose control and macrovascular outcomes in type 2 diabetes. Diabetologia. 2009;52:2288-98.

30. Wanner C, Inzucchi SE, Lachin JM, Fitchett D, von Eynatten M, Mattheus M, Johansen OE, Woerle HJ, Broedl UC, Zinman B. Empagliflozin and progression of kidney disease in type 2 diabetes. N Engl I Med. 2016;375:323-34.

31. Kaku K, Lee J, Mattheus M, Kaspers S, George J, Woerle HJ, Investigators E-RO. Empagliflozin and cardiovascular outcomes in asian patients with type 2 diabetes and established cardiovascular disease - results from EMPA-REG OUTCOME(R). Circ J. 2017:81:227-34.

32. Mosleh W, Sharma A, Sidhu MS, Page B, Sharma UC, Farkouh ME. The role of SGLT-2 inhibitors as part of optimal medical therapy in improving cardiovascular outcomes in patients with diabetes and coronary artery disease. Cardiovasc Drugs Ther. 2017. doi:10.1007/s10557-017-6729-y

33. Zinman B, Wanner C, Lachin JM, Fitchett D, Bluhmki E, Hantel S, Mattheus M, Devins T, Johansen OE, Woerle HJ, et al. Empagliflozin, cardiovascular outcomes, and mortality in type 2 diabetes. N Engl J Med. 2015;373:2117-28.

34. Jardiance PI. Ingelheim B, editor. 2016. p. 1-34.

35. Green JB, Bethel MA, Armstrong PW, Buse JB, Engel SS, Garg J, Josse R, Kaufman KD, Koglin J, Korn S, et al. Effect of sitagliptin on cardiovascular outcomes in type 2 diabetes. N Engl J Med. 2015;373:232-42.

36. Scirica BM, Bhatt DL, Braunwald E, Steg PG, Davidson J, Hirshberg B, Ohman P, Frederich R, Wiviott SD, Hoffman EB, et al. Saxagliptin and cardiovascular outcomes in patients with type 2 diabetes mellitus. N Engl J Med. 2013;369:1317-26.

37. White WB, Cannon CP, Heller SR, Nissen SE, Bergenstal RM, Bakris GL, Perez AT, Fleck PR, Mehta CR, Kupfer S, et al. Alogliptin after acute coronary syndrome in patients with type 2 diabetes. N Engl J Med. 2013;369:1327-35.

38. Pfeffer MA, Claggett B, Probstfield JL. Lixisenatide in type 2 diabetes and acute coronary syndrome. N Engl J Med. 2016;374:1095-6.

39. Neal B, Perkovic V, Mahaffey KW, de Zeeuw D, Fulcher G, Erondu N, Shaw W, Law G, Desai M, Matthews DR, Group CPC. Canagliflozin and cardiovascular and renal events in type 2 diabetes. N Engl J Med. 2017. 377(7):644-657. doi:10.1056/NEJMoa1611925

40. Levine MJ. Empagliflozin for type 2 diabetes mellitus: an overview of phase 3 clinical trials. Curr Diabetes Rev. 2017;13:405-23.

41. Liakos A, Karagiannis T, Athanasiadou E, Sarigianni M, Mainou M, Papatheodorou K, Bekiari E, Tsapas A. Efficacy and safety of empagliflozin for type 2 diabetes: a systematic review and meta-analysis. Diabetes Obes Metab. 2014;16:984-93.

42. Liakos A, Karagiannis T, Bekiari E, Boura P, Tsapas A. Update on long-term efficacy and safety of dapagliflozin in patients with type 2 diabetes mellitus. Ther Adv Endocrinol Metab. 2015;6:61-7.
43. List JF, Woo V, Morales E, Tang W, Fiedorek FT. Sodium-glucose cotransport inhibition with dapagliflozin in type 2 diabetes. Diabetes Care. 2009:32:650-7.

44. Mohammedi K, Potier L, Belhatem N, Matallah N, Hadjadj S, Roussel R, Marre M, Velho G. Lower-extremity amputation as a marker for renal and cardiovascular events and mortality in patients with long standing type 1 diabetes. Cardiovasc Diabetol. 2016;15:5.

45. Paul SK, Klein K, Maggs D, Best JH. The association of the treatment with glucagon-like peptide-1 receptor agonist exenatide or insulin with cardiovascular outcomes in patients with type 2 diabetes: a retrospective observational study. Cardiovasc Diabetol. 2015;14:10

46. Sonesson C, Johansson PA, Johnsson E, Gause-Nilsson I. Cardiovascular effects of dapagliflozin in patients with type 2 diabetes and different risk categories: a meta-analysis. Cardiovasc Diabetol. 2016;15:37.

47. Kosiborod M, Cavender MA, Fu AZ, Wilding JP, Khunti K, Holl RW, Norhammar A, Birkeland Kl, Jorgensen ME, Thuresson M, et al. Lower risk of heart failure and death in patients initiated on sodium-glucose cotransporter-2 inhibitors versus other glucose-lowering drugs: the CVD-REAL study (comparative effectiveness of cardiovascular outcomes in new users of sodium-glucose cotransporter-2 inhibitors). Circulation. 2017;136:249-59

48. Shah AD, Langenberg C, Rapsomaniki E, Denaxas S, Pujades-Rodriguez M, Gale CP, Deanfield J, Smeeth L, Timmis A, Hemingway H. Type 2 diabetes and incidence of cardiovascular diseases: a cohort study in 1.9 million people. Lancet Diabetes Endocrinol. 2015;3:105-13.

49. Fitchett D. SGLT2 inhibitors in the real world: too good to be true? Lancet Diabetes Endocrinol. 2017;5:673-5.

50. Schernthaner G, Jarvis S, Lotan C, Prazny M, Wanner C, Wascher TC. Advances in the management of cardiovascular risk for patients with type 2 diabetes: perspectives from the Academy for Cardiovascular Risk, Outcomes and Safety Studies in Type 2 Diabetes. Ther Clin Risk Manag. 2017;13:69-79

51. Schernthaner G, Sattar N. Lessons from SAVOR and EXAMINE: some important answers, but many open questions. J Diabetes Complicat. 2014;28:430-3.

52. Ferdinand KC, Botros FT, Atisso CM, Sager PT. Cardiovascular safety for once-weekly dulaglutide in type 2 diabetes: a pre-specified meta-analysis of prospectively adjudicated cardiovascular events. Cardiovasc Diabetol. 2016;15:38.

53. Schneider CA, Ferrannini E, Defronzo R, Schernthaner G, Yates J, Erdmann E. Effect of pioglitazone on cardiovascular outcome in diabetes and chronic kidney disease. J Am Soc Nephrol. 2008;19:182-7.

54. Schernthaner G, Matthews DR, Charbonnel B, Hanefeld M, Brunetti P, Quartet Study G. Efficacy and safety of pioglitazone versus metformin in patients with type 2 diabetes mellitus: a double-blind, randomized trial. J Clin Endocrinol Metab. 2004;89:6068-76.

55. Vlckova V, Cornelius V, Kasliwal R, Wilton L, Shakir S. Hypoglycaemia with pioglitazone: analysis of data from the prescription-event monitoring study. J Eval Clin Pract. 2010;16:1124-8.

\section{Submit your next manuscript to BioMed Central and we will help you at every step:}

- We accept pre-submission inquiries

- Our selector tool helps you to find the most relevant journal

- We provide round the clock customer support

- Convenient online submission

- Thorough peer review

- Inclusion in PubMed and all major indexing services

- Maximum visibility for your research

Submit your manuscript at www.biomedcentral.com/submit 